\title{
The Transmigration of the Soul to the American Dream
}

\author{
Vijay K Arora*, Namita Arora Mehta and Vineeta Arora \\ Wilkes University, V’International, USA
}

Received: February 28, 2018; Published: March 13, 2018

*Corresponding author: Vijay K Arora, VInternational, 1896 Pioneer Circle, Lafayette, CO, Chicago, USA, Email: vijay.arora@ieee.org

\begin{abstract}
The American Dream originated from the Columbus discovery of the New World whose original inhabitants he affectionately called Indians as he was looking for Greater India and its vast cultural heritage and aromatic herbs to spice the soul. The connection of the Aryan culture in the Sindh valley of the ancient India, from where the concept of soul originated, is brought live in concert with an article retiled "We Are All Sindhus Now," with substitution Sindhu in place of Hindu, published in Newsweek edition of August 31, 2009. The biology/sociology of world habitat originating from central Asia (perhaps the present day Iran/Iraq) is revealed as the origins of the United States of America (USA) becoming the most powerful nation in the World. The concept of soul, as arising from the bio rhythms of human existence, is analyzed in this paper to give credence to three levels of human existence: gross, subtle and causal body. The soul is the subtle body where all emotions and values reside. A universal secular spirit, the Atma (consciousness), residing in each human being, is the causal body that has to be revered and identified. The concept of soul is highlighted to support secularism and the spirit of human existence that has no color, creed, race or national origin. The recognition of these facts has created wellness in the secular environments of the American Dream as Sindhu beliefs are elaborated on and propagated. The review concludes with the USA claimed as the ideal country in which to advance the concept of soul for the benefit of the humanity, enriched by the ideals of life, liberty, and pursuit of happiness as contained in the Declaration of Independence. Mindfulness as advocated in America is discovery of thoughtfulness of our actions, conceived or undertaken. A recipe in following these principles in personal and professional life is given.
\end{abstract}

Keywords: Soul of Education; American Dream; Indian Dream; Human Development; Spiritual; Renewal; Avatar; Vision; Dharma; Serendipity; Secularism

\section{Introduction}

The discovery of America was serendipity as Christopher Columbus [1]. Was in voyage to discover Greater India and its vast resources. His objective was to sail west until he reached Asia (the Indies) to fulfill his Indian Dream, where the riches of gold, pearls, herbs and spices awaited. The India of his dream was vast, full of resources and knowledge of its elite universities. Not knowing the direction without a compass, he went the other way and landed in the New World in 1492. His Indian Dream turned over to the American Dream as he landed the shores of America with the warm welcome of the original inhabitants. Columbus affectionately called them Indians, believing he has discovered India. It was actually a Bahamian island, the south of present North America. His expedition went ashore the same day and claimed the land for Isabella and Ferdinand of Spain, who sponsored his attempt to find a western ocean silk route to China, India and the fabled gold and Spice Islands of Asia. It was a serendipitous discovery that followed mass migration from Europe to escape fanaticism. That is how New Amsterdam was born, later renamed New York as British arrived with full artillery. The American Indians became the earliest identified inhabitants, believed to have entered the North American continent through an icy Siberian passageway that once existed between northeastern Asia and the region now called Alaska. During four separate trips that started with the one in 1492, Columbus landed on various Caribbean islands that are now the Bahamas as well as the island later called Hispaniola. He also explored the Central and South American coasts. He never thought he had found a new continent with North America, a part of Americas.

\section{Rise of the Sindhus}

The Sindh is a river and a province, now in Pakistan, that was an integral part of British India before 1947. The Aryans who settled in the Sindh Valley came from central Asia (perhaps Iran/Iraq of modern times as an Aryan, predecessor of a Sindhu is well-known there). We call them Sindhus for two reasons. Firstly, 'Sindhu' means 'ocean'. They created an ocean of wisdom from their knowledge documented in the Vedas, the ancient scriptures of India. Secondly, 
Sindh culture evolved into what we call Sindhuism that with twisted pronunciation became Hinduism resulting in rituals, which is accidentally portrayed as a pluralistic religion worshipping many gods. Yet, there is third reason to call them Sindhus; they crossed the oceans to create an influential Sindhu Diaspora all over the world. We know no country on this planet where Sindhu influence is not present. In fact, Sindhuism, rekindling spiritual Hinduism, gives the freedom to think and be free from bondage to any god or goddess, even liberates Sindhus from their birthplace to search for knowledge, wisdom and innovation. Sindhus were deeply engrossed in reasoning through dialogue [2]. Cites a commentary on cover page of his book from The Pioneer of 8 March 1894, an American newspaper. The Pioneer calls them genuine Hindus which is equivalent to what we call Sindhus. Their presence made Greater India not only the centre of knowledge, but also gave her the wisdom to bring happiness to all human beings leading to Sat Chit Ananda (existence-awareness-bliss). Renowned scholars of the past converged around the renowned universities of Nalanda (more on this in Soul of Education section), Taxila and Mohenjo-Daro in the zest to find the soul of human existence, Atma, the all-pervasive consciousness. Soul and Atma are often taken to be synonymous, but they are different. This distinction will become clear when we see soul as subtle body (sukhasam srira) and Atma as causal body (karan srira) andan individual seen as a gross body (sathul srira) by the world. All three are in relationship with one another.

\section{The Soul of Education}

If a civilization like that of the Sindhus of the Sindh (Indus) valley were to be destroyed, the first thing to do would bet attack the educational institutions to make people ignorant, as this will make ruling over them easier. This method of making people ignorant is found to work in favor of rulers, including priests, who boast of their knowledge and prowess in giving instructions to followers. Mao Zedong renewed the spirit of the Chinese Revolution, fearing that China would develop along the lines of the Soviet model, as he was concerned about his own place in history. Schools and colleges were closed and the economy started to suffer. Similarly, all the famous universities of India were leveled by invaders. That became the beginning of the end of the Indian Dream as prosperity in all forms evaporated and wealth looted by invaders. Nalanda University [3]. Was founded in 427 AD. Many non-resident Indians (NRIs) are doing concerted effort to revive it to original glory. Nalanda University has been a renowned centre for learning from the 5th century until it was destroyed by Bakhtiyar Khilji in the 12th century. Garten proclaims, "One of the most important universities in the world, was developed not in the medieval west, but right here in India: Nalanda University... was instrumental in producing people who are capable of understanding and articulating what it means to have universal knowledge, knowledge that is applicable across cultures and across times." That was the Indian Dream turning into an American Dream as ideas propagated towards Western hemisphere [3].

Notes in New York Times, "It [Nalanda] was devoted to Buddhist studies, but it also trained students in fine arts, medicine, mathematics, astronomy, politics and the art of war. The university was an architectural and environmental masterpiece. It had eight separate compounds, 10 temples, meditation halls, classrooms, lakes and parks. It had a nine-story library where monks meticulously copied books and documents so that individual scholars could have their own collections. It had dormitories for students, perhaps a first for an educational institution, housing 10,000 students in the university's heyday and providing accommodation for 2,000 professors. Nalanda was also the most global university of its time, attracting pupils and scholars from Korea, Japan, China, Tibet, Indonesia, Persia and Turkey. Its demise was a result of waning enthusiasm for Buddhism in India, declining financial support from successive Indian monarchs and corruption among university officials." The burning of the buildings by Muslim invaders from what is now Afghanistan was the final straw for its demise. That was beginning of the extinction of Indian Dream.

Lord Macaulay on February 2, 1835 [4], Recited to the British Parliament, "I have travelled across the length and breadth of India and I have not seen one person who is a beggar, who is a thief, such wealth I have seen in this country, such high moral values, people of such caliber, that I do not think we would ever conquer this country, unless we break the very backbone of this nation, which is her spiritual and cultural heritage and therefore, I propose that we replace her old and ancient educational system, her culture, for if the Indians think that all that is foreign and English is good and greater than their own, they will lose their self-esteem, their native culture and they will become what we want them, a truly dominated nation." Some believe it not to be authentic address. However, the facts speak for themselves as it is compatible with the state of India before several invasions. Dharma (conduct of duties with high ethical standards) principles were prevalent in the minds of Indians before India was invaded.

The gurukula (home of guru the teacher) system of education with ongoing debates and dialogues was a common learning process. It was built on dharma principles. The authoritarian rule, turning away from Gurukula culture, was heard with quotes similar to "do not ask why; either do or die." That set the tone for British education in India. British education was structured with strict rules. American education [5]. On the other hand, relied on dialogues, discussion, and problem solving. The British, ruling the colonial world, had no intention to make the reigned ones thinkers and dreamers. They wanted them to be clerks, who followed orders. American education leaves room for questioning the established paradigms. The American Dream [6,7]. Is now being embraced as Washington Accord. The Washington Accord [7]. Is a mutual recognition agreement, which pertains to engineering programs, accredited by its signatories in their jurisdictions since 1989. Signatories to the Washington Accord are organizations responsible for accrediting engineering programs in Australia, Canada, China, Chinese Taipei, Hong Kong China, India, Ireland, Japan, Korea, Malaysia, New Zealand, Pakistan, Russia, Singapore, South Africa, Sri Lanka, Turkey, the United Kingdom, and the United States. Many more countries are provisional members, aiming to 
get the full signatory status. That shows the soul of the American Dream is now attractive all over the globe $[5,8]$.

Illuminating Indian Dream of 5000 years of science and innovation notes "From some of the earliest cities to interplanetary exploration, Indian innovation in science, technology and mathematics has dramatically shaped the world we live in today." That is exactly what American Dream is bringing out. Sindhus, following the dharma principles, were extremely spiritual in unearthing the forces that drove them towards finding a mission, vision and values of human enterprise. In some versions of history books and bible, Jesus Christ is stated to join Sindhu forces to advance the concept of happiness and contentment [9]. Learnt, while he was in Ladakh, that there existed ancient records of the life of Jesus Christ. In the course of his visit at the great convent, Notovitch located a Tibetan translation of a scholarly document entitled 'The Life of St. Issa'. Jesus is seen as Issa Masih in India, are incarnation of Buddha, the wise. 'Bodh', or sometimes written as 'bodha' in English, is wisdom and one who has attained wisdom with an enlightened mind is called the Buddha. In that context Sindhus are Buddhas. Jesus is Buddha [9]. While quoting Jesus a reluctant messenger, reveals that Jesus spent 17 years in India and Tibet. From age 13 to age 29, he was both a student and teacher of Buddhist and Sindhu holy men. The story of his journey from Jerusalem to Varanasi was recorded by Brahman historians. At the spiritual level, Christianity, Judaism, Sufism and Sindhuism are similar, all originating from the Zoroastrian view of soul. The rituals and engaged practices turn the spirituality into a religion. As rituals are repeated, these get embedded in the mind of practicing people of particular sect. It is easier to manage people by putting the fear of god or goddess in their mind. The priests may propagate the concept of sin and proclaim that they are the ones who are competent to get rid of those sins, of course with a price to pay. Jesus' followers created a doctrine of Christianity. As many practicing pundits arrived on the scene, differences of opinions bifurcated into many sects of the same religion. Catholic sect is the result of these bifurcations as it believed in universality.

Sindhus of early days managed ideas, not people or religions, leading them towards change, considering change to be the only constant that traditions cannot survive. Our bodies are changing and with the rise of the Internet, our thought processes are changing. As travel becomes ubiquitous, many cultures are mingling to create new ones, including through inter-racial marriage. The evolution of catholicity as the universality of acceptance is clearly visible in Pope Francis' sermons and many of the displays in the Vatican. With enhanced understanding, in practicing Sindhu principles, scholars are continuously engaged in debate to document what is beyond the gross body. That is how Sindhu scriptures were born. Mind, the collection of attitudes, is Brain's software. Indian scriptures are replete with dialogues between a Guru or teacher and a disciple. The Bhagwad Geeta is the dialogue between Krishna as a Guru and Arjuna as his devotee. In 18 chapters, the context keeps changing to illuminate the fact that what we are looking for externally is present within us in the consciousness (Atma).
Tat twam asi (that is you) is what Bhagwat Geeta unfolds in each chapter. Text and its context are well integrated in each chapter. That is why each chapter is yoga of particular characteristic. [10]. discuss the emerging facts from successful organizations, including universities, indicating Sindhu principles the real source of power in a knowledge-based economy. They combine technological prowess with entrepreneurship that may be spiritual in the sense of launching ideas into motion. It talks about turning the traditional quantitative-verbal thinker to a future-oriented visionary by redirecting the whole-brain thinking. Critical success factors in the development of an effective and efficient wise workers displaying wisdom for the 21st century are enumerated by [10]. Management of ideas initiate through thinking and generating alternatives. The choice is to pick the best alternative through prioritization.

\section{Sindhu Doctrine}

The soul of the Sindhu doctrine in America originated from research by Lisa Miller [11]. In the Newsweek edition of August 15, 2009. Lisa Miller, as a scholar, followed the survey to document the public opinion. The summary of her research findings were published as "America is not a Christian nation. We are, it is true, a nation founded by Christians, and according to a 2008 survey, 76 percent of us continue to identify as Christian (still, that's the lowest percentage in American history). Of course, we are not a Hindu-or Muslim, or Jewish, or Wiccan-nation, either. A million-plus Hindus live in the United States, a fraction of the billion who live on Earth. But recent poll data show that conceptually, at least, we are slowly becoming more like Hindus and less like traditional Christians in the ways we think about God, ourselves, each other, and eternity. The Rig Veda, the most ancient Hindu scripture, says this: "Truth is one, but the sages speak of it by many names." A Hindu believes there are many paths to God. Jesus is one way, the Qur'an is another, and yoga practice is a third. None is better than any other; all are equal. The most traditional, conservative Christians have not been taught to think like this. They learn in Sunday school that their religion is true, and others are false. Jesus said, "I am the way, the truth, and the life. No one comes to the father except through me."

Americans are no longer buying it. According to a 2008 Pew Forum survey, 65 percent of us believe that "many religions can lead to eternal life"-including 37 percent of white evangelicals, the group most likely to believe that salvation is theirs alone. Also, the number of people who seek spiritual truth outside church is growing. Thirty percent of Americans call themselves "spiritual, not religious," according to a 2009 NEWSWEEK Poll, up from 24 percent in 2005. Stephen Prothero, religion professor at Boston University, has long framed the American propensity for "the divine-delicafeteria religion" as "very much in the spirit of Hinduism. You're not picking and choosing from different religions, because they're all the same," he says. "It isn't about orthodoxy. It's about whatever works. If going to yoga works, great-and if going to Catholic mass works, great. And if going to Catholic mass plus the yoga plus the Buddhist retreat works, that's great, too." Then there's the question of what happens when you die. Christians traditionally believe that bodies and souls are sacred, that together they comprise the "self," 
and that at the end of time they will be reunited in the Resurrection. You need both, in other words, and you need them forever.

Hindus believe no such thing. At death, the body burns on a pyre, while the spirit-where identity resides-escapes. In reincarnation, central to Hinduism, selves come back to earth again and again in different bodies. So here is another way in which Americans are becoming more Hindu: 24 percent of Americans say they believe in reincarnation, according toa 2008 Harris poll. So agnostic are we about the ultimate fates of our bodies that we're burning them-like Hindus-after death. More than a third of Americans now choose cremation, according to the Cremation Association of North America, up from 6 percent in 1975. "I do think the more spiritual role of religion tends to deemphasize some of the more starkly literal interpretations of the Resurrection," agrees Diana Eck, professor of comparative religion at Harvard. So let us all say "om."”

North Americans have not, we know, openly converted en masse to Sindhuism- even if Elizabeth Gilbert's book [12]. About exploring Indian mysticism, Eat, Pray, Love, has become a hugely popular movie, and the lead actress, Julia Roberts, declared that she is Hindu. The book and the movie has inspired and empowered millions of readers to search for their own best selves. In her early thirties, Elizabeth Gilbert had everything a modern American woman was supposed to want-husband, country home, successful career-but instead of feeling happy and fulfilled, she was consumed by panic and confusion. This wise and rapturous book is the story of how she left behind all these outward marks of success, and set out to explore three different aspects of her nature, against the backdrop of three different cultures: pleasure in Italy, devotion in India, and on the Indonesian island of Bali, a balance between worldly enjoyment and divine transcendence. The point is that Sindhus do not embrace one religion or one process. It is ongoing search for what is right. The dialogue is to find what is right. The argument is to find who is right. Religious scholars embrace arguments in support of rituals; Sindhus embrace dialogue to uncover spirituality [11]. Will read better if Hindu is replaced with Sindhu in the spirit of what she found from her research. That is also authors' vision of Secular America and its Dream that touches the soul of everyone in the free world. In that spirit, most forward-looking Americans are Sindhus, who may be equated to the Nones movement in vogue in America. Sindhuism is also the soul of Buddhism as many superstitions were swamping the spiritual values of Hinduism to cater to personal interests of ecclesiastics. Sindhuism is a remedy to accentuate spirituality that comprises knowledge, wisdom, and ongoing reasoning. One may infer that Sindhuism is the soul of Hinduism or as The Pioneer [2]. Pronounces genuine Hinduism [13].

Speech to the World Parliament of Religions in 1893 at Chicago is exemplary. In his opening address, he tried to persuade that Sindhuism is a yoga, the integration, in the true spirit of engineering human thoughts to embrace the one-ness of the Atma, the consciousness around which other factors of human existence revolve or evolve., Vivekananda, in authors' opinion, imperfectly portrayed Hinduism as a religion, in place of what he was preaching as Sindhuism, the spiritual force behind every living being [13].
Through his speeches, tried to consolidate various religions by focusing on Sindhu doctrines [2]. quoting from The Pioneer, an American newspaper of 8 March, 1894, comments, "By far the most important and typical representative of Hinduism was Swami Vivekananda, who, in fact, was beyond question the most popular and influential man in the Parliament [of Religions] on all occasions he was received with great enthusiasm, than any other speaker, Christian or "pagan', the people thronged him wherever he went and hung with eagerness on his every word.

Since the Parliament, he has been lecturing before large audiences in principal cities of United States [of America] and received an ovation wherever he went Never before has so authoritative a representative of genuine Hinduism-as opposed to emasculated and Anglicized versions of it so common in these days-been accessible to American inquirers; and it is certain, beyond peradventure, that the American people at large will, when he is gone, look forward to eagerness to his return...America thanks India for sending him, and begs him to send many more like him." With the rise of Sindhuism as a secular force, it appears Vivekananda thoughts are bring reincarnated. Vivekananda (18631902) was one of the greatest monks of India, who had suggested ways to create a healthy synthesis of the Western Science and Eastern Philosophy. In Vivekananda words [2]. "Teach yourself; teach everyone his (or her) real nature. Call upon the sleeping soul and see how it awakes. Power will come, glory will come, goodness will come, purity will come, and everything that is excellent will come, when this sleeping soul is roused to self-conscious activity." His famous words echo through the heart of Sindhus, "Arise, awake and stop not till you reach the goal".

It is remarkable how Sindhu beliefs, metaphysics and practices have quietly seeped into American culture; without Americans knowing it, they are embracing the American Dream in compliance with the Indian Dream as practiced by the Aryans of Sindh valley through ongoing dialogues. It may be seen as osmosis or diffusion of Sindhuism into American secularism. Yoga studios, meditation centres, vegetarian restaurants and ayurvedic health spas, all have roots in Sindhuism. Even Buddha was a devout Sindhu who challenged the evolved Hindus. He was considered an atheist and was chased out of India. He became Buddha after acquiring bodh the wisdom that is true enlightenment. In this context, science and spirituality overlap as both are searching for truth. Sindhuism, as what Nones believe, brings us closer to enlightenment or salvation. It gives us incredible freedom to think or reason out through dialogue. It does not make one less a Sindhu because one worships plants or the sun in as far as one recognizes the all-pervading consciousness present in these objects. It sets one on the right path through thinking, deliberation, meditation, and integration (This is yoga!) with the transmigrating soul and ever-present timeless Atma.

\section{Avatar-the Reincarnation}

Mark Barian [14]. Resident teacher at Arsha Bodha Centre, gives a clear description of the transmigrating soul from one body to the other. 'Arsha' means coming from the rishis (sages) and 'bodh' or 
'bodha' is wisdom. His name was changed to Swami Tadatmananda (one who believes in the bliss of Atma) when he embraced Sindhuism, 'Swami' meaning 'master'. Two metaphors mentioned by [15]. Deal with the concept of the soul's identification with the subtle body. In one metaphor he used in a You-Tube video as shown in (Figure 1). The Sun is portrayed as Atma the causal body; this may be seen in the analogy of a barrel of water. The water in the barrel is the subtle body from which the Sun rays are reflected or absorbed. The barrel holding the water is the gross body. The barrel is simply a piece of wood that is without value if it has nothing to hold. The water gives its value. The water, the subtle body, can be transferred from one barrel to another as the old one is discarded and a new one put in its place. The old one may be discarded because the wood has perhaps rotted and the barrel has become leaky and is no longer able to hold water. Water, the subtle body, escapes. It is possible for the water to reflect or absorb the rays of the Sun (analogue to causal body, the Atma) through the presence of the subtle body. The barrel the gross body finds its usefulness only when the subtle body is present in order to feel the presence of the Sun, the causal body.

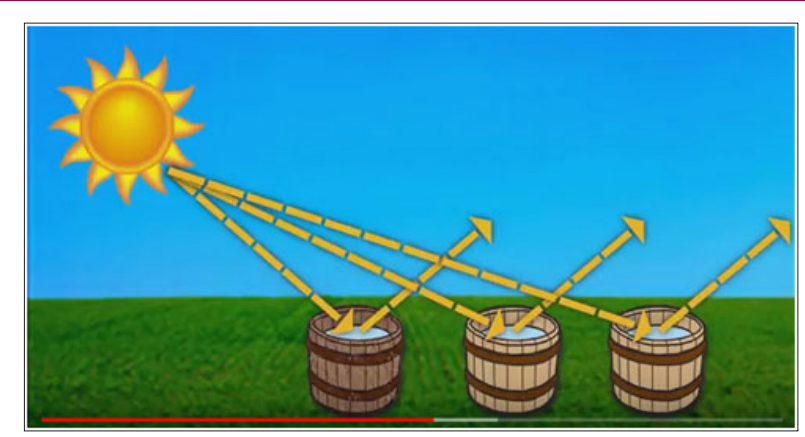

Figure 1: A metaphor displaying the Sun as causal body the all-pervasive consciousness, the reflection from water in the barrel the subtle body that can travel from one barrel to the other one, and barrel the gross body.

Similarly, the brain, the gross body, finds its existence through the mind, the subtle body. Prana, the power of walking and talking, is the causal body. The five senses that each human being possesses are subtle. The sensors are the eyes (sight), ears (hearing/listening), tongue (taste), nose (smell), and hands (touch). The subtle body travels from one body to the other as one dies and is reincarnated. Atma does not travel, it is stationary ever-present or timeless. So far as the subtle body is present in the gross body, one is alive. Similarly, the brain is gross, but the mind and thought patterns that programmers the brain is subtle. One may call the mind the soul of the Brain. It is the subtlety where happiness resides and one attains Sat Chit Ananda.

In the second metaphor in his You-Tube Video, as shown in (Figure 2). Swami Tadatmananda brings out vividly the concept of subtle and gross by comparing computer software and hardware. Gross comprises the power supply, the central processing unit (cpu) and the hard disk. The power supply is the heart of the gross body that is computer, while the tangle of wires is the arteries and veins, the CPU is the brain, and the hard disk is the memory. The gross body the computer will have no function without the software, the subtle the soul of computer hardware. A one-pound hard disk with a capacity of $20 \mathrm{~GB}$ will not weigh more as more software is added to it as the software is subtle. If the computer is not plugged in, it will not work. Electricity is the all-pervasive consciousness that operates the computer, allowing the software to become accessible. Nothing will happen if the computer lacks software even if the computer is plugged in. Old computers (gross body) that do not work are discarded and the software that gives them a function and purpose is then transferred to a new computer.

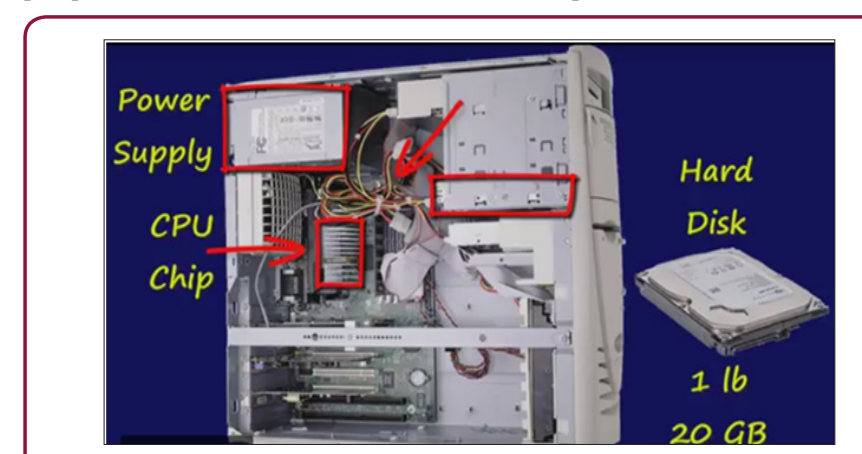

Figure 2: Metaphor displaying electricity as causal, software as subtle, and hard disk as gross.

In the same way, the soul, the subtle body, and travels as software from one computer to another is transferred to the new one as old hardware becomes obsolete or dies and is replaced with new hardware. Even the soul, the software, has to be renewed from time to time; we call this procedure an upgrade. So too the programming of our brain as the times change need to be upgraded; this we now call change management. Reincarnation is the belief that the soul is reborn in many, many lives as it transmigrates from one body to another after death. Knowing this, we approach death as a meditation and a spiritual opportunity. It is disastrous that modern science disjoints the triads, gross-subtle-cause, as understood in Sindhu philosophy. In fact, medical training should include the inter-dependence of the triads in practice [16].

Damasio in his superbly written and scientifically sound book entitled, Descartes' Error, corrects Rene Descartes, the famed French mathematician, by linking the subtle and the gross. Descartes believed that the gross did not need the subtle to function, heightening respect for machine-like qualities of the body, a concept that is part of modern medical training and hence the cause of many ill-conceived notions. The most frustrating fact of modern science, as elaborated by Benson [17]. Is that it stays pegged to the question, "What we are made of?" The answer is always the looks of, the cells, and the bones of the gross body. The subtle body comprises a rich gamut of moods and ideas, passions and values that run through it like signals that are sometimes corrupted by noise from other factors. The goal is to keep the signal-to-noise ratio high so that the subtle body signals have their chance to propagate without added noise. The causal body is a mystery that to a certain extent, is organically controlled, which is in fact energizing the whole universe. The energy drives living entities. This non-identification of the causal body has given birth to various religions that may perceive the causal body as a god or goddess or variations of such beings. Some may even call it the 
placebo effect powered by affirmative belief: "Yes, I will recover. I am capable of healing myself." From its Latin root, 'placebo' means "I shall be pleasing or acceptable," which applies equally well for care-givers and receivers, again in the spirit of Sindhu dialogue. Just like as our subtle body can perceive wellness (placebo), it can also perceive sickness and death (nocebo). Such an effect is termed psychosomatic. Sindhu principles promote the concept of placebo.

\section{Roots of Wisdom}

Wisdom originates from correct application and management of knowledge. The path of gaining wisdom starts with collecting the data through research, categorizing the data to get information, and putting the mind into it to gain knowledge. The knowledge is of little use unless it is applied. The wisdom arises from spreading knowledge in time and space domain, when and where needed (Figure 3). Explains how collected data can become information when it is categorized. Knowledge is derived from the information engineering. Enhanced understanding leads us to wisdom. The wisdom leads to self-management. Self-management is the key in building relationships. An enlighten manager will provide strong leadership in propagating a goal-driven engineering process an engine of invention, innovation, and growth. The needs of a healthy human enterprise ought to take priority over wealth creation. Management by walking, travelling or exploring exposes one to disapprovals. However, that is the soul or sole purpose of discovering serendipity. The word serendipity also arises from the Indian text and context. Sri Lanka, once a part of Greater India, was once the golden island (swarna dip). The discovery of Sri Lanka by traders is termed serendipity after swarna dip. Serendipity became exploration of gold (what is valuable) from what is trash. Although some of life's lessons are learnt in carpe diem (seize the day), other lessons become apparent only after the moment has passed. Americans are investing heavily in the practice of yoga as an integrative lifestyle where prana (the lifeline, sometimes called 'soul' or in its infinitive form 'Atma'), mind, and body are integrated into the timeless infinite which most mortals refer to as God or Goddess.

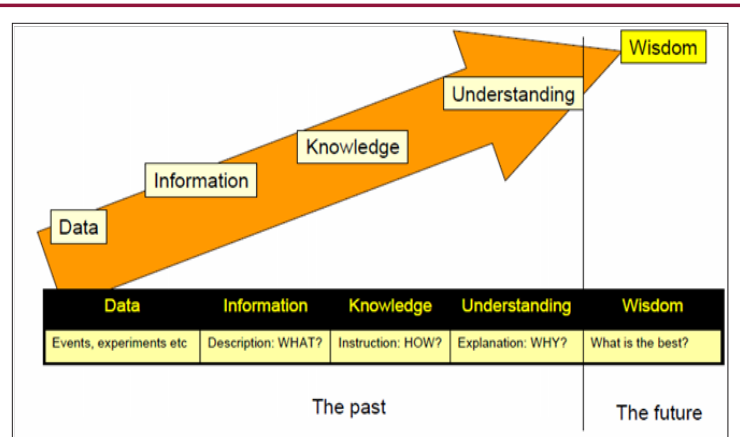

Figure 3: Data, information, knowledge, and cognitive engineering from the past leads to wisdom in engineering the future.

(Figure 4) Indicates how hostility reduces the power of reasoning, while synergy multiplies the benefits Human wants are insatiable and resources on planet Earth are constrained. This is in fact a principle of the Theory of Constraints on how to manage oneself as resources at the disposal of any human beings are limited and sometimes restricted. Global warming is one ongoing issue in the international arena where Earth resources are limited and their flagrant use is causing unwanted weather patterns. The engineering design is a paradigm of managing constraints in the light of limited resources, both material and human. 'Engineering' word has its origin in ingenious from Latin. An engineer-entrepreneur [10], Is an engine of growth, driving several compartments as he or she does multitasking. Here, comes the soul of management that is centered on a given person. Every living human being has a quality in him or her that needs to be honed to be a good manager. The eastern philosophies from Indo-China propagated to America have become embedded in the theory and practice of organizational behavior. Professionals not so successful in their country of birth achieve remarkable success on migrating to America and creating an American Dream for themselves and for all others in their circle of influence as they synergies. That is why America is the land of opportunity. Where else in the world would one find such a fusion of the best in the world? Here, immigrants get an opportunity to practice simultaneously the text (the soul of management) and context (entrepreneurial environments in which the text will be utilized) [18]. In an article in Physics Today of August 2007 on p. 49 concluded, "The practice of religion must be a matter of choice for the individual, not enforced by the state. This leaves secular humanism, based on common sense and the principles of logic and reason, as our only reasonable choice for governance and progress. Being scientists, we understand this easily. The task is to persuade those who do not." Hoodbhoy's statement has omission that Sindhu principles are not understood even by the scientists. Scientists and engineers even though expected to synthesize ideas for assimilation, are hostile on a number of incidences reported. They create glitches by ignoring spirituality or the soul, the subtle body, in favor of gross. The fake data or unsupported conclusions are shown to give what [19].

\begin{tabular}{|l|l|l|}
\hline Types of interaction & Math formula & Outcome \\
\hline Synergy & $1+1=3,10,100$ & Transformation \\
\hline Compromise & $1+1=1 \frac{1}{2}$ & Transaction \\
\hline Defensiveness & $1+1=1 / 2$ & Contention \\
\hline Hostility & $1+1=-1,-10,-100$ & \\
\hline
\end{tabular}

Figure 4: Hostility to synergy with stated positive or negative outcomes.

Call sits an impure science. This impure science creates a lot of anomalies. Ignoring the testing of an O-ring in space shuttle Challenger resulted in its blow-up in space, for example. Bell charges that all aspects of our welfare, social and military infrastructure are threatened by extensive fraud, secrecy and fierce competition for research funds from government and industry. While whistleblowers are penalized, he notes, especially for exposing such costly fiascos as the space shuttle and the Hubble telescope, control measures-e.g., replication, peer and journal reviewing--are prone 
to abuse, as are the grant-awarding procedures of the National Science Foundation, the Pentagon and Congress. Among the author's sometimes over-detailed examples--such as the case of scientific data faking which forced Nobel Prize winner David Baltimore to resign the presidency of Rockefeller Institute-Bell also condemns drug companies for gross violation of FDA regulations. The author's very tentative solutions call for excluding peers from investigations, providing increased protection for whistle-blowers and meting out stiffer penalties for offenders. Ignoring the existence of Atma makes one chase wealth without evaluating its context or values. The media, perhaps, are to blame in labeling wealth the key success factor over and above spirituality. That is why the 10 richest people gain more prominence than the 10 most spiritual people.

Intelligent design is one such contemporary issue that is being debated at the crossroads of science, engineering and spirituality where sometimes Einstein's secular thoughts are shared in scholarly discourses [20]. A well-known writer and secular Guru tried to reconcile Sindhuism and secularism with modern science. Chopra deepened his theme of the healthy-soul-healthy-body link by examining the mysterious phenomenon of spontaneous remission of cancer. Using quantum physics as a means of understanding the subtle-gross-cause connection argued that consciousness (Atma) is the basic foundation of nature and the universe. Separation of church and state is not the same as separation of awareness (divine presence) and the state. A critical mass of Sindhus who band together in their spiritual and secular worldview can defeat the age-old addiction to war and turf protection that continues to create mass suffering. In Chopra's reconditioned words on p. 24, "It's time to rescue intelligent design from the politics of religion.

There are too many riddle not yet answered by either biology or the religious doctrines and by debating them honestly as Sindhus, without preconceived conclusions, yoga and meditation engineering could take a huge leap forward." When we think of success and wealth, what comes to our mind are our material comforts and their abundance buried therein. While such comforts are an integral part of success and wealth, they are meaningless without a consideration of spiritual happiness. True success means material and financial wealth coupled with enjoyment of life's journey, a continued expansion of happiness, and the progressive realization of worthy goals. In the American Dream, freedom of expression is enjoyed and a dialogue can continue to distinguish right from wrong without imposing any threat or death sentence on anyone. The times have changed the acceptance of those freethinking ideas.

This framework of free expression encourages constructive dialogues to discover one-self by the self and for the self by continued enquiry into the processes of human evolution and revolution. Ancient wisdom encourages continued dialogue (iztihad in Arabic and swanda in Sanskrit) that all people and organizations must embrace in response to the changing times as new discoveries come to light. It may be called change management, transformation engineering or renewal science; whichever term will fit the Endeavour well. An effective exchange of ideas in managing knowledge at the crossroads of science, engineering, management and spirituality is a must for all stakeholders. The emerging facts from successful organizations indicate that the real source of power in a knowledge-based economy is the management of ideas. The choice is stark: educate, innovate or evaporate. The assurance of life, liberty, and pursuit of happiness for all Americans (even nonAmericans living in the USA and elsewhere) is contained in the Declaration of Independence.

Equal-opportunity principles using diverse talents made America the most powerful nation on planet Earth. The principles of equal opportunity were crafted after the nation went through a wretched history of slavery and fighting for women's rights, including suffrage, segregation, etc. The civil war and recent dialogues on confederacy are some of the elements that teach us equal opportunity principles. America's leadership has been of great value to the world, but is being questioned under the leadership of President Donald Trump and Russia's interference in deciding the election outcomes, as reported in the media during February 2018. Sindhuism in America actually inspires people to love their fellow men and women and motivates them to serve humankind gladly. Albert Einstein said, "The goal of a religion is to develop free and responsible individuals so that one may place one's powers freely and gladly in the service to humankind." A spiritual framework with a soul in a secular setup is a personal relationship between the creation and the creator, whether or not a person belongs to an organized sect.

A religion respecting Sindhu forces of nature can combine the one-ness or non-duality (Atma) of classical Sindhuism with the spirit of equality of Islam and the spirit of service of Christianity, for example [11]. Assimilates this concept very well. The choice is for people to decide whatever works for them. America became the world's role model in part because of a political system that recognizes individual rights and responsibilities in maintaining a free and moral society. Even today, Americans hold on to a personal ethical system that emphasizes honesty, personal responsibility, tolerance, and good citizenship. However, a system putting unusual demand on individuals, undermine their ethical behavior and hence the quality of their work. Even Japan, well-known for its Total Quality Management, is facing a quality breakdown as its workforce is subjected to stress and manipulations. A strong correlation between the quality of a person and the ethics (dharma) he/she holds to has been shown. If one generalization about leadership and change is to be made, it is this: no change can occur without willing and committed followers. It is the internal drive of a disciplined people that drives an organization of the people, by the people, and for the people.

Dharma is a profound word in Sanskrit expounding on ethical conduct. However, it is wrongly translated as 'religion' even by Indians who are exposed to Sanskrit. An ethical problem can be solved just like an engineering problem. The VCR (V for Values and Virtues, $\mathrm{C}$ for Consequences and Contingencies and R for Rights and Responsibilities) paradigm developed at Carnegie-Mellon University is one possible platform for the solution of an ethical 
dilemma. The VCR paradigm allows one to evaluate an action before executing it, as stipulated by the law of dharma. It gives a platform for an individual on which to assess values and virtues of the community one lived in prepares him for possible consequences of his actions with associated contingency plans. The R in VCR gives the rights of decision-making to those who take the responsibility for their actions. In training professionals on work ethics, the emphasis should be on finding ways to build strong character in professionals or the organization they serve with the intention to build trust and enhance trustworthiness among the stakeholders. After all, an efficient and reliable economic and political system is always based on a moral foundation. This principles-based leadership approach not only enhances our effectiveness, but it also creates a healthy society that will judge professionals by their contributions to humanity.

\section{Engineering the Future}

Working in teams and following a directed approach towards problem solving, professionals will improve not only the standard of living, but also the standard of life for all their customers and for others who are yet to come within their circle of influence. Standard of life means feeling the subtle body or soul in a person (including one's 'self'). In an ancient Indian dialogue between a teacher and a pupil entitled Tatavabodha (essence of wisdom), the discriminating power between nitya (timeless or ever present) and anitya (transient or time-bound) is enlightened. This scripted dialogue climaxes three levels of gross-subtle-causal of any human being. Each one of us is recognized by the gross body, made of five original elements: earth, air, water, space and fire (temperature). It is endowed with six fold modification: it exists, is born, grows, undergoes modifications, decays and dies. It has five sensors of perception: the ear, the skin, the eye, the tongue and the nose. Utilizing these sensors, we can use the subtle body for effective communication, thereby improving the standard of life. The causal body is that which is indefinable and without any beginning. It is the cause of two bodies (gross and subtle). It is that superpower from which all religions originate and description of god evolved in its present varied forms. That is timeless Atma (sometimes loosely defined as 'soul') and forms a common thread among all living beings and drives us all. In that context, we are all engineered entities. In search of innovation to enhance creativity, synthesizing the artificial forces of humans and the divine forces of nature will play an active role and become the yoga, the integration. As natural (God-made) and artificial (man-made) processes are understood and synthesized, there will be even greater need for a programmed approach while solving problems in the natural habitat of organizations anywhere in the World [21]. As we conclude grosssubtle-causal amalgamation to paint an expression of the self, we should contemplate the following resolutions for personal and professional success:

a. While planning for success, each one should consider himself or herself a contributing member of a larger enterprise. Our success is driven by how we talk, look, write, listen, create ideas, solve problems, motivate, persuade, lead, organize, handle anger and other negative emotions and deal with power figures and other organizations. In this capacity, we will be connoisseurs of talents, more curators than creators. Add motive and determination to achieve a goal, and we will progress towards that goal.

b. We will get out of our cubicle by communicating effectively with people who may or may not think and operate the way we do. We must realize that human nature is such that silence is deafening and curiosity overwhelming. The silence of a person is an indication that he or she is shaken psychologically and emotionally for a variety of reasons. We can ignite the curiosity in a silent colleague who is identified as not participating with enough enthusiasm. It is like creating resonant behavior by matching the 'frequency' of the driver with the driven.

c. We should keep on reminding ourselves as to what is important in engineering our future. Not only will we produce quality attributes among our 'customers', we will also create a quality educational organization by relating to our colleagues and by forming effective and efficient teams. Here by 'customer' we mean whosoever is in our circle of influence. As members of a team, we should remain intimate allies of our colleagues and peers at large. We may not have the loudest voice but we should have the most attentive ears. The ingredients are a combination of our competence, commitment, caring, fairness, candor and generosity.

d. We should harness the tremendous informationprocessing capability of our three-pound three-quart-sized internal computer, our brain, estimated to have about 17 billion bytes of storage and operating at 100 times the speed of computers. We should not waste this powerful knowledgemanaging resource for self-cancellation of our own endeavors with our own selfish motives. We should enhance the creativity of this nature-given resource with a value system to give all stakeholders what they need to succeed and live a meaningful life. We should use our mind-powered software to soul the brain's hardware.

The integration of gross-subtle-causal forces as practiced on the Silk Route that extended from Mediterranean to China is now being recognized as we unite science and spirituality. Perhaps one way of bringing peace, prosperity and intellectual growth to the planet is by reviving the cultural cohesion of the Silk Route model of cosmopolitanism. The Chinese were intrigued by invoking those secular forces by practicing the principle of gross-subtlecausal integration for political empowerment, consolidation of power and the well-being of people. Mantra chanting is repetition of noble vibrations and feelings. We are what we repeatedly do to gain excellence. Combining power with virtue was a new concept for oriental countries, where Buddhism was welcomed. It still continues to be a divine force in Japan as Japanese feel ashamed if quality of the product or service is not good. Japan has grasped the concept of Total Quality Management. Buddhism provided the cohesive culture and is cosmopolitan. 
It is indeed gratifying to discover one's own 'Silk Route' through the discovery process of thinking about possible alternatives and consequences. Gratitude has become a great attitude lifting us to greater altitude. Gratitude means counting our blessings, being thankful and acknowledging everything that we received on our custom-made Silk Route. It is living our life as if everything were a miracle and being aware non-stop of how we have been blessed by others. Gratitude shifts our focus from what our life lacks to the richness that it already enjoys. As simple as it sounds, gratitude is actually a multi-faceted emotion that requires self-reflection, the ability to admit that one is dependent upon the help of others and the humility to realize one's own limitations. Buddha's bounty is ever present on habitually grateful people as all are children of God; being male or female does not matter as God itself is love for all, a concept that cannot be defined through figures or words. Buddha is a symbol of any wise person. It is that wisdom that removes ignorance and makes us enlightened. In that spirit, we are all Buddhas in discovering the truth [21]. Has many hilarious ways to describe human folly by not recognizing the Sindhu principles.

\section{Final Word}

Both science and spirituality are designed to discover truth through the process of enquiry, dialogue, teamwork, sanctity and open communication without any fear of retribution in the Final Word chapter of his book cited what Buddhists chant:

a. Buddham Sharnam Gachammi (Be in the protection of embodiment of wisdom)

b. Dharmam Sharnam Gachammi (Be in the protection of ethical conduct)

c. Sangam Sharnam Gachami (Be in the protection of noble people

In the spirit of following the path of righteousness, following advice is in line with the Sindhu principle to fire the soul into action:

a. Sindhu Bhav (Be an ocean of wisdom)

b. Dharmam Char (Follow the path of righteousness or ethical conduct)

c. Yogastha Kuru Karmani (Establish yourself in total integration of gross-subtle-cause, to perform an action and any action)

The first set is the vision of Buddhists to seek refuge (sarangati in Sanskrit). The second set is action with a vision on what needs to be done to be a devout Sindhu. As Joel Barker said, "Vision without action is merely a dream; action without vision just passes the time; vision combined with action changes the human enterprise."

Combining vision of the sages with our continued actions, following the dharma principles, will bring us closer to eternity. After all, it is our Great Attitude of Gratitude, not our Aptitude that will take us to a Greater Altitude for the shukhasam srira (soul) to connect with the causal srira (Atma, the consciousness). Research has shown that habitually grateful people have more energy, optimism, social connections and happiness. They earn more money, sleep more soundly, exercise more regularly and have a stronger immune system. We should practice Namaste (I bow to the divinity in you) with gratitude [22]. Namaste is a new word that crept into the American dictionary. Its spiritual meaning is, "when you meet anyone, treat the event as a holy encounter." We should make every encounter we have today or tomorrow an opportunity to see the divine within ourselves and others by saying Namaste [23-28]. Give converging paradigms in behavioral and social engineering in shaping human thought processes in selfmanagement and managing people around the self.

\section{Acknowledgement}

The connection of science and spirituality arose during VKA's Asia travels when he was a distinguished visiting professor at the University Technology Malaysia 2007-2015. He expresses his heartfelt gratitude to then Vice-Chancellor Zaini Ujang (now Secretary General, Ministry of Energy, Green Technology and Water) for showing his leadership in inaugurating case studies as are done in the Harvard Business School. The Director General, Siti Hamisah, at the Malaysian Ministry of Education and erstwhile UTM Deputy Vice-Chancellor deserves special words of appreciations for sharing some of the ideas contained in the paper. Ujang's office created the graphics contained in the paper. Giving thanks to Ujang and Hamisah is more than just a polite move: It is transformation of our mood, outlook, and health too (keeping authors young and vibrant in generating ideas). We are counting our blessings in knowing them and working with them in bringing Malaysia to the World at large. The authors are indebted to Swami Tadatmananda in pointing us to his downloadable You-Tube video with its clear explanation of the transmigrating soul. His clarity of explanation of the gross and subtle body and the cause of human existence is beyond parallel. The authors also thank Arsha Vidya Gurukulam (http://www.arshavidya.org) in Saylorsburg, Pennsylvania, USA, in bringing to America the vast heritage of the sages whom we designate Sindhus. The authors benefitted from the lectures of Swami Dayananda Sarasawati (deceased) who was conferred the title of Padma Vibhushan (posthumously) by the Prime Minister of India, Narendra Modi. Swami Tadatmananda (previously Mark Barian) was a student of Swami Dayananda Saraswati along with each of the authors in learning the Sindhu doctrine stated here. It was taught as 'Vedanta' (the end of the Vedas) or the Final Word of the Vedas or the Vision of the Vedas.

\section{References}

1. History (1492) Columbus reaches the New World.

2. Shuddhidananda Swami (2012) Vivekananda as the Turning Point: Rise of a New Spiritual Wave. The Pioneer, An American Newspaper, USA.

3. Garten Jeffrey E (2006) Really Old School. Page A19 of the New York edition with the headline.

4. (2008) Sunday Post, Lord Macaulay's Speech on Indian Education: The Hoax \& Some Truths.

5. Arora N, VK Arora (2015) Life-Long Education for the Global Workforce in the Socio-Engineering Age. Pertanika Journal of Social Sciences and Humanities 23(1): 3-27. 
6. Arora Vijay (1998) Integration of Liberal Arts, Management, and Technical Skills for Professional Development Session 3261, American Society of Engineering Education (ASEE).

7. (2018) ABET, The Accreditation Board for Engineering and Technology, Global Presence.

8. Science Museum (2018) Illuminating India: 5000 Years of Science and Innovation.

9. Notovitch Nicolas (2008) The Unknown Life of Jesus Christ, Wilder Publications, New York, USA

10. Arora VK, L Faraone (2003) $21^{\text {st }}$ century engineer-entrepreneur, IEEE Antennas and Propagation Magazine 45(5): 106-114.

11. Miller Lisa (2009) We Are All Hindus Now, Newsweek, New York, USA.

12. Gilbert Elizabeth (2007) Eat Pray, Love: One Woman's Search for Everything Across Italy, India and Indonesia, Riverhead Books, USA.

13. Vivekananda Swami (1893) Sisters and Brothers of America.

14. Barian Mark (2018) Vedanta, Bhagavad Gita, Meditation, Yoga, Sanskrit, Vedic Chanting

15. Tadatmananda Swami (2017) Reincarnation: who is that travels?

16. Damasio Antonio R (1994) Descartes' Error:Emotion, Reason, and the Human Brain. Penguin Books, New York, USA.

17. Bensen Herbert (1996) Timeless Healing: The Power and Biology of Belief, Simon and Schuster, New York, USA.

18. Hoodbhoy Perwez (2007) Science and the Islamic World, Physics Today, American Institute of Physics, New York, USA, 9: 49.

(c) This work is licensed under Creative Submission Link: https://biomedres.us/submit-manuscript.php
19. Bell Robert (1992) Impure Science: Fraud, Compromise and Political Influence in Scientific Research, John Wiley \& Sons 92(3): 401-405.

20. Chopra Deepak (2002) Ageless Body, Timeless Mind: The Quantum Alternative to Growing Old, Better World Books, Mishawaka, Indiana.

21. Adams S (2000) The Dilbert Principle: A Cubicle's-Eye View of Bosses, Meetings, Management Fads \& Other Workplace Afflictions, Pan Macmillan Publishers, New York, USA.

22. Dyer Wayne (2005) The Power of Intention, Hay House, USA

23. Arora VK, N Arora (2014) Converging paradigms in behavioral and social engineering, in Recent Trends in Social and Behavior Sciences $p$. 3-8.

24. Arora VK (2009) Engineering the Soul of Management in the Nano Era. Chinese Management Studies 3: 213-234.

25. Arora VK (2012) OBE and WA: Understanding the Paradigm Shift on Knowledge, Journal of Engineering, Science \& Management Education 5: 430-444.

26. Arora VK (2013) Educating Tomorrow's Authentic Global Leaders: Converging Paradigms in Science, Engineering, Management and Liberal Arts, a 30-minute audio-visual presentation.

27. Arora VK (2015) Nanoelectronics: Quantum Engineering of LowDimensional Nanoensembles, Appendix K, CRC Press, Taylor and Francis Group, France.

28. (2018) Nalanda University, Vision.

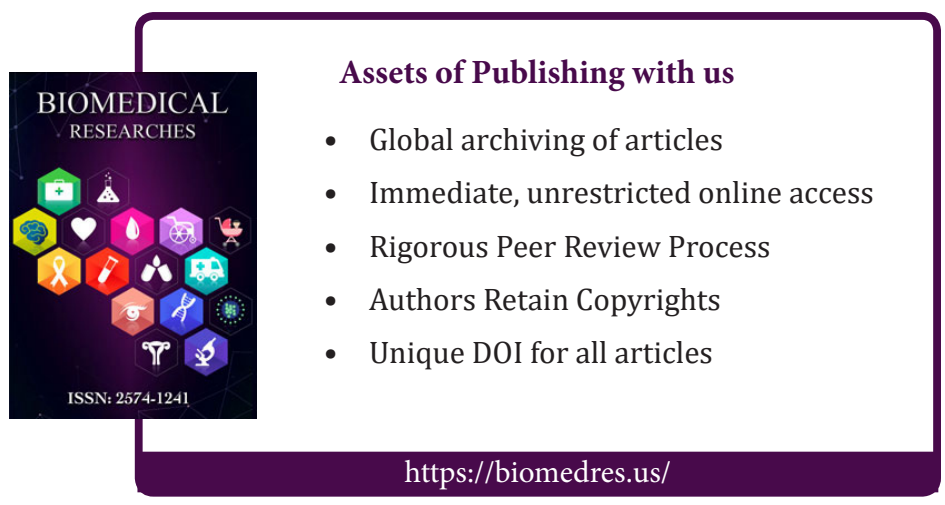

